International Review of Research in Open and Distributed Learning Volume 21, Number 1

January -2020

\title{
Book Review: High-Impact Practices in Online Education
}

Editors: Kathryn E. Linder and Chrysanthemum M. Hayes (Sterling, VA: Stylus Publishing, 2018, 221 pages) ISBN: 978-162036-847-3 (paperback)

Reviewed by: Emily K. Faulconer, Embry-Riddle Aeronautical University - Worldwide Campus, Daytona Beach, FL

High-Impact Practices in Online Education, edited by Kathryn E. Linder and Chrysanthemum M. Hayes, presents a comprehensive discussion of how to translate impactful educational experiences to the asynchronous and synchronous online classroom. The first work of its kind, this volume is useful to educators across the disciplines, administrators, educational researchers, and instructional designers. The collection is rich with examples of high impact practices (HIPs) in online learning environments, with each well-researched chapter prepared by credible authors focusing on a specific HIP. The editors expertly ensured a coherent voice across the chapters.

The introduction presents a strong premise for the work (pp. 2 -3):

- The demand for high-quality college degrees is increasing;

- The demographic profile of the degree-seeking student is becoming more diverse;

- Over the last 13 years, the number of students taking distance courses has steadily increased; and

- Online students are expecting more.

Instead of viewing HIPs as individual practices, the editors present a constellation of HIPs that, when approached as milestones along a students' academic career, has a cumulative effect, particularly as the key transferable skills employers desire the most in graduates. This vision is presented in Figure I.1, which charts the 11 HIPs by increasing student independence and critical thinking skills.

Aligned with the constellation of HIPs, this book starts with the foundational HIPs, those with lower student independence, complexity, and critical thinking. Chapter 1 explores first-year seminars by first laying out the key criteria for a successful experience based on traditional firstyear experiences. The chapter ends with a call for research in this area to establish reach and outcomes of online first-year seminars.

The authors then point to a gap in the literature on other first-year experiences delivered online beyond seminars. In Chapter 2, the authors present the use of "big questions" from the Narrative, Engagement, Transformation (NET) framework in general education courses to achieve a common intellectual experience online. Following this, online learning communities are discussed in Chapter 3 where the authors present a key concept: "There is a critical semantic distinction between fostering a community of learners through educational strategies supported by technologies and the design of a learning community (LC) - the intentional linking of college courses and assignments as a means of fostering curricular coherence and deep, integrated learning" (pg. 41). The strategy presented - using "big questions" as a 
linkage in an interdisciplinary course or a block of courses appeared to be very similar to the NET framework from Chapter 2, only with more emphasis on the learners and less on the content.

HIPs that require moderate student independence and critical thinking include writing intensive courses, collaborative projects, and undergraduate research. Because online classes are already very text-heavy, quality of writing prevails over quantity. Chapter 4 highlights what makes writing activities in online courses high-impact, including clearly communicated high performance expectations, authentic tasks, frequent constructive feedback, and structured reflection. Suggested approaches for the online classroom include peer review and screencast technology for feedback delivery. Chapter 5 explores the challenges to collaborative learning in the asynchronous environment, including communication gaps, technical difficulties, and the authenticity of the collaboration (all of which are also valid concerns in traditional courses). The chapter authors present strategies to support clear online communication within the group and how to make grading criteria explicit. Chapters 6 and 7 explore undergraduate research in online humanities and science courses. While Chapter 6 discusses a single example, Chapter 7 provides multiple suggestions for obtaining data for research at a distance. A key concept underlined by the authors is scaffolding research skills throughout the curriculum.

Towards the end of a student's academic career, they have gained increased independence and critical thinking. These skills support higher level HIPs, including diversity and global learning, service-learning, internships, capstone courses, and e-portfolios. Chapter 8 tackles the somewhat nebulous idea of diversity and global learning, which could take many forms. The authors boil it down to active learning, with a focus on multiple strategies for supporting interaction among students. The authors note the challenges in online learning, including the heavy dependence on written communication that restricts non-verbal communication. While the suggested strategies of a community scavenger hunt and jigsaw groups seem viable, the international partner class seems less attractive due to logistics. Chapter 9 presents the limited body of research on eService Learning hybrids while acknowledging the barriers. Tables 9.2 and 9.3 offer strategic suggestions for how to translate the traditional service-learning experience online. As an educator who used service-learning in my traditional teaching and who has struggled to reimagine it for the asynchronous online environment, this chapter offered solid suggestions like starting small, considering how the service is executed (integrated, component, or stand-alone), and selecting a community partner. I would have liked to see more discussion about how to identify a community partner and project that is suited for online execution. Chapter 10 establishes that online internships, while under-researched, appear to have the same best practices as traditional internships, including faculty and professional supervisors, defined goals, feedback, and self-reflection. Table 10.1 is a critical resource to anyone considering supervising or administering an online internship. Interestingly, and breaking from the previously discussed HIPs, online capstones (discussed in Chapter 11) show improved student outcomes compared to traditional capstone courses. The authors present the best practices from the nationally recognized program at Portland State University. In Chapter 12, the authors explore the benefits of e-portfolios to address two significant problems in online education: connectedness and communication. The authors deftly identify e-portfolios as a remedy to programmatic evaluation required for accreditation. Students benefit from a platform that supports metacognition, reflection, and synthesis by connecting learning across courses and extra-curricular learning. 
I approached High-Impact Practices in Online Education as an online educator and active SoTL researcher with a particular interest in undergraduate research, collaborative learning, and eService learning. Overall, this work was objective and thorough while striking a balance between the discussion of high-impact practices and their context in online spaces. The key takeaways at the end of each section are a nice touch, making the work even more useful. However, there was some redundancy in the background of each chapter and the book would have been equally effective with less emphasis on establishing the validity of the HIPS in traditional learning environments in the beginning of each chapter. Additionally, if you are looking for more practical advice for day-to-day teaching of an online course, you may not find it as prescriptive as some others such as, Aaron Johnson's (2013) the Excellent Online Teaching: Effective Strategies for A Successful Semester Online.

Still, I strongly believe in that the High-Impact Practices in Online Education achieved its goal of making online HIPs tangible by presenting the current research and emerging practices. I recommend this book to all online educators and administrators - and to anyone who says, "but you can't do that online." 


\section{Reference}

Johnson, A. (2013). Excellent online teaching: Effective strategies for a successful semester online. Retrieved from https:// www.amazon.com/ Excellent-Online-Teaching-Strategies-

$\underline{\text { Successful/dp/ } 0989711609}$

\section{Athabasca}

University

(c) 